\title{
Molecular simulation of adsorption of alkanes in sodium MOR-type zeolites using a new force field
}

\author{
Bei Liu*ab and Berend Smit ${ }^{a b}$ \\ Received 16th December 2005, Accepted 8th February 2006 \\ First published as an Advance Article on the web 24th February 2006 \\ DOI: $10.1039 / b 517774 j$
}

\begin{abstract}
The applicability of a recently proposed force field of Calero et al. (J. Am. Chem. Soc., 2004, 126, 11377) to Na-MOR zeolites is evaluated. The Henry law coefficients of ethane and $\mathrm{C}_{5}-\mathrm{C}_{9}$ as well as the adsorption isotherms of ethane, propane, butane, and hexane in various Na-MOR zeolites are computed and compared with experimental values. These comparisons show that the new force field is suitable for Na-MOR zeolites. Furthermore, this force field is used to study the effects of sodium cations on the adsorption behavior of larger alkanes, such as $\mathrm{C}_{4}-\mathrm{C}_{7}$, in MORtype zeolites. These simulations give a better understanding of the underlying mechanisms of the cations' position and density influence on adsorption. In addition, a characteristic pressure named "reversal pressure" is introduced which characterizes the efficiency of the presence of cations in zeolites.
\end{abstract}

\section{Introduction}

Zeolites are microporous materials that have found widespread applications in many fields, particularly in heterogeneously catalyzed processes in the petrochemical industry. Mordenite (MOR) is a particularly useful zeolite for several catalytic applications, such as dewaxing of heavy petroleum fractions and cracking or isomerization of hydrocarbons. ${ }^{1}$ It can be synthesized with a large range of different $\mathrm{Si} / \mathrm{Al}$ ratios, where the anionic character of the lattice caused by the substitution of silicon by aluminum is compensated by cations. The presence of cations influences the adsorption and the catalytic properties of this type of zeolites. The type, density, and location of non-framework cations can be tailored by adjusting the $\mathrm{Si} / \mathrm{Al}$ ratio and synthesis approaches, leading to tailored adsorption and catalytic properties.

The sodium form of MOR-type zeolites (Na-MOR) is commonly used in practical applications. Although many experimental investigations have been performed on the adsorption properties of $\mathrm{Na}-\mathrm{MOR}$ zeolites, ${ }^{2-12}$ our understanding of the effects of cations on the adsorption properties at the molecular level is as yet incomplete. Molecular simulations might be a suitable tool to complement experimental efforts. However, so far a limited number of simulations have been performed on the adsorption properties of alkanes in Na-MOR zeolites, mainly due to the absence of suitable force fields. Most of these simulations deal with small alkanes only. For example, Smit and den Ouden ${ }^{13}$ performed a Metropolis Monte Carlo (MC) study of small molecules in $\mathrm{Na}-\mathrm{MOR}$, Macedonia et $a l^{9}{ }^{9}$ studied the adsorption isotherms of methane, ethane, and argon in $\mathrm{Na}-\mathrm{MOR}$ zeolite by the grand-canonical Monte Carlo (GCMC) simulation method.

${ }^{a}$ Centre Européen de Calcul Atomique et Moléculaire (CECAM), Ecole Normale Supérieure, 46 allée d'Italie, 69007 Lyon, France

${ }^{b}$ Van't Hoff Institute for Molecular Sciences, University of

Amsterdam, Nieuwe Achtergracht 166, 1018 WV Amsterdam, The

Netherlands.E-mail: bliu@science.uva.nl
Beerdsen et al. ${ }^{14}$ on the other hand, used the configurationalbias Monte Carlo (CBMC) method to investigate the influence of non-framework sodium cations on the adsorption of $\mathrm{C}_{1}-\mathrm{C}_{4}$ in MOR-type zeolites. It is well known that large alkanes are important in petrochemical processes; however, so far simulations on alkanes larger than $\mathrm{C}_{4}$ have been performed only on a purely siliceous representation of MOR, ${ }^{15,16}$ hence, without considering the influence of cations on adsorption.

It is commonly recognized that reliable force fields for the interatomic potentials play a key role in molecular simulations. As a result, many force fields ${ }^{17-22}$ have been proposed for the interactions between the adsorbates and the zeolite framework and for the adsorbate-adsorbate interactions. Recently, Calero et al..$^{23}$ developed a united-atom force field, able to accurately describe the adsorption properties of linear alkanes in the sodium form of FAU-type zeolites. In this force field the nature, density, and mobility of the non-framework cations, the density of the framework aluminum, and all host-guest interactions are carefully taken into account, and good agreement was obtained between experiments and simulations. This force field gives a very good description of the interactions between alkanes, sodium cations in FAU-type zeolites; however, as the force field is based on a set of superimposed empirical potentials of which the parameters have been fitted to experimental data directly and no mixing rules are used, the values of these parameters may have different values than one would expect if one compares the individual value with other sets of parameters. For example, the positively charged $\mathrm{Na}$ ion has a strength parameter, $\varepsilon / k$, which may look surprisingly high for a "non-polarizable" molecule and the $\mathrm{Na}-\mathrm{CH}_{3}$ interaction has a relatively high dispersion interaction. If such values would be completely unphysical, it would be very unlikely that transferring these potentials to other systems would give equally satisfactory results. Therefore, it is necessary to test the applicability of this force field to other zeolite structures. Recently, García-Pérez et $a l .{ }^{24}$ have successfully reproduced the adsorption properties 
of alkanes in a sodium-exchanged MFI structure using this force field, encouraging us to test its applicability to the Na-MOR zeolites.

The aim of this work is threefold. The first aim is to validate a suitable force field for $\mathrm{Na}-\mathrm{MOR}$ zeolites, for which we evaluate the recently proposed force field by Calero et al. against experimental data and also existing simulations using other force fields whenever possible. The second aim is to use the validated force field to study the relationship between sodium cations and the adsorption behavior of butane in MOR-type zeolites. Finally, the adsorption behavior of larger alkanes such as $\mathrm{C}_{5}-\mathrm{C}_{7}$ is investigated, based on the force field of Calero et al. to give insight into molecular-level details of the influence of the location and density of cations on the adsorption.

\section{Simulation models and methods}

\subsection{Mordenite zeolite models}

In order to compare with experimental data directly, four $\mathrm{Na}-\mathrm{MOR}$ unit cell compositions were used in the simulations, varying the $\mathrm{Si} / \mathrm{Al}$ ratio: $\mathrm{Na}_{8} \mathrm{Al}_{8} \mathrm{Si}_{40} \mathrm{O}_{96}$ (the maximum amount of $\mathrm{Al}$ in the structure), $\mathrm{Na}_{6} \mathrm{Al}_{6} \mathrm{Si}_{42} \mathrm{O}_{96}, \mathrm{Na}_{2} \mathrm{Al}_{2} \mathrm{Si}_{46} \mathrm{O}_{96}$, and $\mathrm{Na}_{0} \mathrm{Al}_{0} \mathrm{Si}_{48} \mathrm{O}_{96}$. The structure corresponding to $\mathrm{Na}_{8}$ was taken directly from the work of Meier et al. ${ }^{25}$ Zeolite structures with lower framework-aluminum densities were obtained by randomly removing $\mathrm{Al}$ atoms and replacing them with $\mathrm{Si}$ atoms, following the criteria of previous works. ${ }^{26,27}$ Through this procedure, the Löwenstein rule is automatically observed and it affords a reasonable approximation of the framework aluminum distributions obtained by experimental methods. The zeolite lattices were assumed to be rigid in the simulations, because the flexibility of the framework has a negligible influence on the adsorption of alkanes. ${ }^{28}$

\subsection{Force field}

The force field used in this work is the united-atom force field recently proposed by Calero et al. ${ }^{23}$ The alkanes are described with a united-atom model, in which $\mathrm{CH}_{3}$ and $\mathrm{CH}_{2}$ groups are considered as single, charge-less interaction centers. ${ }^{29}$ The beads in the chain are connected by harmonic bonding potentials. A harmonic cosine bending potential models the bond bending between three neighboring beads, and a Ryckaert-Bellemans potential controls the torsional angle. The interactions between the adsorbates as well as the adsorbates and the zeolite are described by Lennard-Jones potentials, and the interactions between the sodium cations and the zeolite are modeled by Coulombic potentials. The parameters used are listed in Table 1. For a detailed description of the force field, the reader is referred to ref. 23 .

\subsection{Simulation technique}

For the calculation of Henry law coefficients we performed configurational-bias Monte Carlo (CBMC) simulations in the $N V T$ ensemble. Each simulation consists of at least $4 \times 10^{7}$ cycles and in each cycle one move is chosen at random with a fixed probability of 0.1 for a molecule translation, 0.1 for rotation around the center of mass, 0.1 for partial regrowth of
Table 1 Force field parameters used in this work ${ }^{a}$

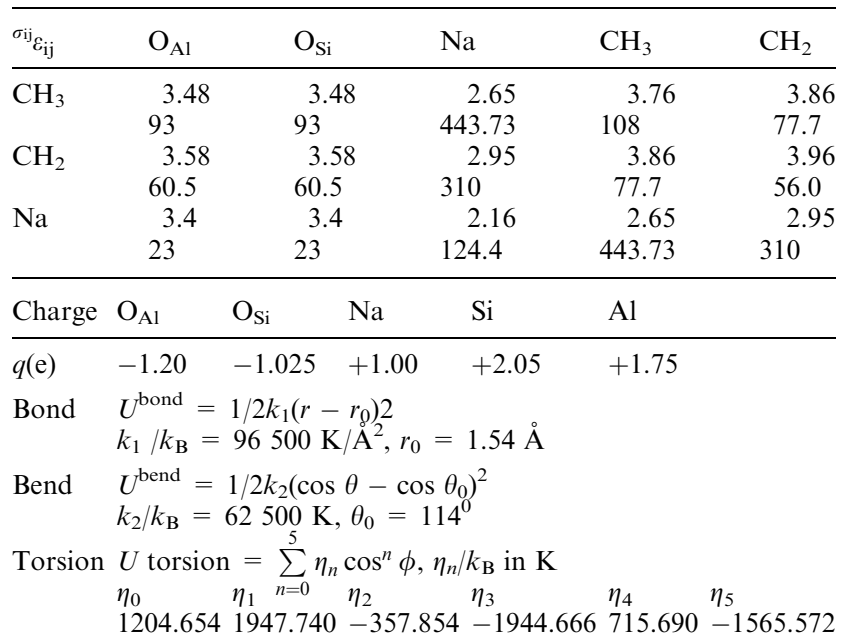

${ }^{a}$ All parameters listed in this table are taken from ref. $23 . \sigma_{\mathrm{ij}}[\AA]$ value is in the upper right corner and $\varepsilon_{\mathrm{ij}} / k_{\mathrm{B}}[\mathrm{K}]$ is in the lower left corner of each field. The partial charges $[e]$ of the framework and the sodium cations are given at the lower part of the table. $\mathrm{O}_{\mathrm{Al}}$ are oxygen atoms bridging one silicon and one aluminum atom, and $\mathrm{O}_{\mathrm{Si}}$ are oxygen atoms bridging two silicon atoms.

a molecule, and 0.7 for regrowth of the entire molecule. During the simulation we compute the Rosenbluth factor, which is directly related to the Henry law coefficient. ${ }^{30}$

Adsorption isotherms were calculated in the grand-canonical ensemble using the CBMC method. The CB-GCMC method simulates an open system specified by fixed temperature $T$, volume $V$, and fugacity $f$. We converted the imposed fugacity to the corresponding pressure using the Peng-Robinson equation of state. Four types of moves were carried out: translation, rotation, exchange of molecules between the zeolite and a molecule reservoir, and partial regrowths. All simulations included at least $2 \times 10^{7}$ cycles. As the total number of cations is constant during simulations, only translation movements and regrowth at a random position in the zeolite are considered for these particles.

The statistical uncertainty was estimated by dividing each run into 5 blocks and calculating the standard deviation from the block averages. The standard deviation was within $\pm 2 \%$ for every simulation. A detailed description of the simulation methods can be found in our previous work. ${ }^{14,19,22,23}$

\section{Results and discussion}

\subsection{Validation of the new force field for $\mathrm{Na}-\mathrm{MOR}$ zeolites}

As a first step towards validation of the applicability to $\mathrm{Na}-\mathrm{MOR}$ zeolites of the new force field proposed by Calero et al. for $\mathrm{Na}-\mathrm{FAU}$ zeolites, the Henry law coefficients of ethane and linear $\mathrm{C}_{5}-\mathrm{C}_{9}$ in $\mathrm{Na}_{8} \mathrm{Al}_{8} \mathrm{Si}_{40} \mathrm{O}_{96}$ were calculated and compared with experimental ${ }^{7,9}$ and simulation ${ }^{9,14}$ results, as shown in Table 2 and Fig. 1. The new force field shows improved results over previous simulations for ethane and the calculated results for $\mathrm{C}_{5}-\mathrm{C}_{9}$ are also in good agreement with 
Table 2 Henry law coefficients $\left[\mathrm{mg} \mathrm{g}^{-1} \mathrm{kPa}^{-1}\right]$ of ethane in the MOR-Na8 zeolite

\begin{tabular}{llll}
\hline$T / \mathrm{K}$ & 273.15 & 296.15 & 323.15 \\
\hline Experimental data $^{9}$ & 79.103 & 23.984 & 7.783 \\
This work & 89.100 & 26.850 & 8.940 \\
Macedonia et al. (simulation data) $^{9}$ & 61.744 & 15.905 & 4.157 \\
Beerdsen et al. (simulation data) $^{14}$ & 90.667 & 28.965 & 9.023 \\
\hline
\end{tabular}

the experimental values obtained by Denayer et al., ${ }^{7}$ illustrating this force field is suitable for $\mathrm{Na}-\mathrm{MOR}$ zeolites.

To test the applicability of the new force field further, the adsorption isotherms of ethane, propane, butane, and hexane were computed and compared with experimental data, ${ }^{2-4,8}$ as shown in Fig. 2-5. The number of sodium cations and the temperature used for each isotherm were chosen in such a way as to allow a direct comparison with experimental data.

The experimental adsorption isotherms of ethane and hexane in MOR zeolite with $8 \mathrm{Na}^{+}$cations as obtained from the literatures $^{2-4}$ are shown in Fig. 2 and 3, in which our simulated results are also presented. Our computed isotherms are in good agreement with the experimental ones for all the temperatures considered.

Additional isotherms were calculated for the MOR zeolites, with $2 \mathrm{Na}^{+}$, for propane at $373 \mathrm{~K}$ and for butane at $438 \mathrm{~K}$. These results are shown in Fig. 4 and 5, respectively, with the experimental data $^{8}$ for comparison. Since there are several possible MOR structures with $2 \mathrm{Na}^{+}$, the simulation results were obtained by averaging over different aluminum-atom arrangements in the simulation cell (details of the method are given in section 3.2). To illustrate the importance of including cations in the simulation, we have also performed some calculations on the purely siliceous structure. Experimentally, it is observed that, at a given temperature and pressure, the amount of adsorption increases with increasing sodium density at low and intermediate loadings. Our simulations give a correct trend and are in good agreement with the experimental data. ${ }^{8}$

The simulation results of adsorption isotherms together with those of Henry law coefficients show that the force field

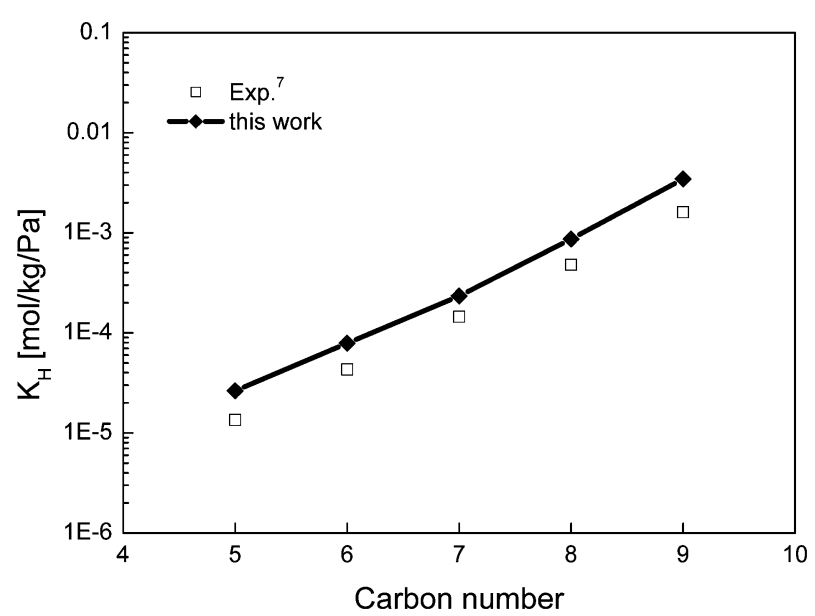

Fig. 1 Comparison of the experimental ${ }^{7}$ and simulated Henry law coefficients $K_{\mathrm{H}}$ for $\mathrm{C}_{5}-\mathrm{C}_{9}$ in MOR-Na8 zeolite at $598.15 \mathrm{~K}$.

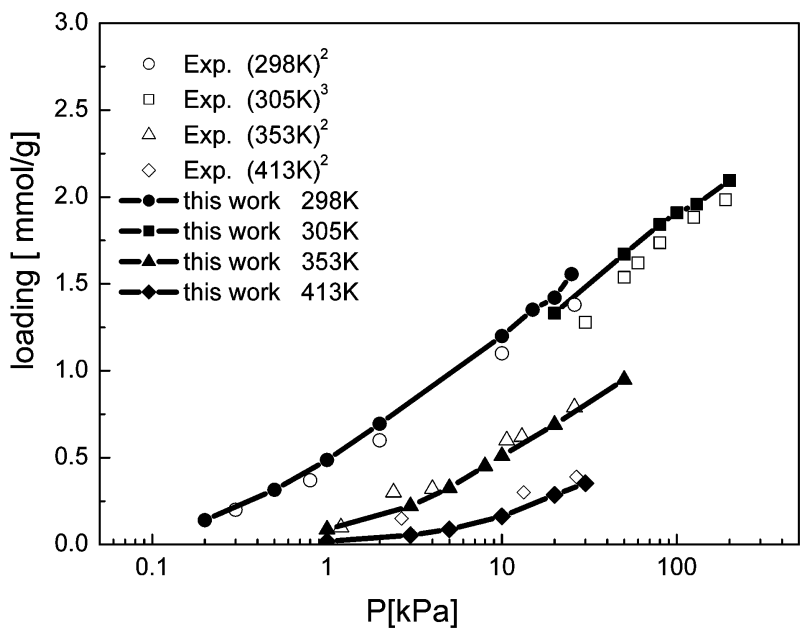

Fig. 2 Comparison of the experimental ${ }^{2,3}$ and simulated adsorption isotherms of ethane in MOR-Na8 zeolite.

of Calero et al. is applicable for the characterization of $\mathrm{Na}-\mathrm{MOR}$ zeolites.

\subsection{Relationship between cation location and alkane adsorption}

To study the effects of the cation location on the adsorption behavior, we performed simulations to obtain the adsorption isotherms of butane in six different $\mathrm{Na}-\mathrm{MOR}$ structures with 6 sodium cations per unit cell (CBV 10A, Zeolyst ${ }^{\mathrm{TM}}$ Product) at $343 \mathrm{~K}$. The results are presented in Fig. 6. Experimentally, it has been observed that the distribution of sodium cations in CBV $10 \mathrm{~A}$ is essentially random. ${ }^{12}$ As the positions and stability of sodium cations in the zeolite are strongly related to its $\mathrm{Al}$ distribution, ${ }^{31}$ three of the six structures we have considered, were obtained by randomly removing $\mathrm{Al}$ atoms from the structure corresponding to 8 sodium cations per unit cell and replacing them by silicon atoms (structures $1-3$, in Fig. 6), while the remaining three were built randomly from

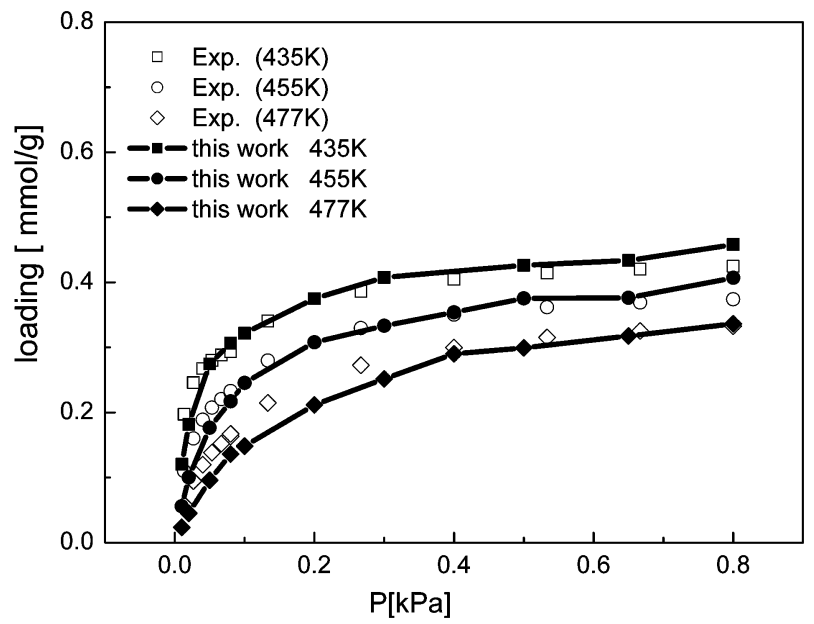

Fig. 3 Comparison of the experimental ${ }^{4}$ and simulated adsorption isotherms of hexane in MOR-Na8 zeolite. 


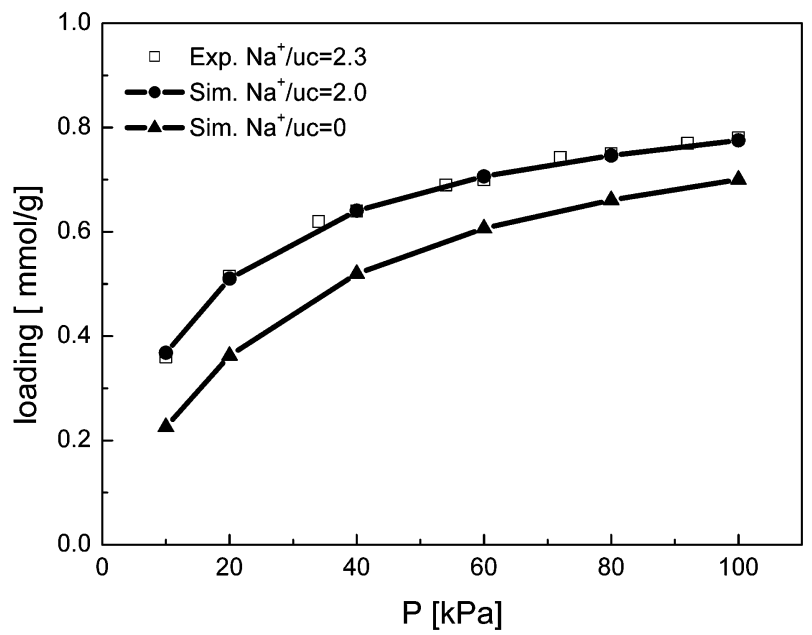

Fig. 4 Comparison of the experimental ${ }^{8}$ and simulated adsorption isotherms of propane in MOR-Na2 zeolite at $373 \mathrm{~K}$.

silicon, aluminum and oxygen following the criteria of previous works ${ }^{26,27}$ (structures 4-6 in Fig. 6).

Fig. 6 shows that when the pressure is higher than $10 \mathrm{kPa}$, the six structures give nearly identical results. However in the pressure range of $0.01-10 \mathrm{kPa}$, the six structures show different results. Since the side pockets, the small side channels parallel to [010] with $8 \mathrm{AlO}_{4}$ or $\mathrm{SiO}_{4}$ cross sections, are not accessible for larger alkanes, ${ }^{32,33}$ adsorption tends to be limited to the main channels. Structure 4, where all 6 sodium cations are located in the main channels, presents the highest adsorption capacity, while structures 5 and 6 , with a large amount of aluminum on the crystallographic site $\mathrm{T} 3$, corresponding to the sodium cations near site I, i.e. in the small side channels, ${ }^{27,34}$ give the lowest adsorption capacity. This illustrates that the presence of non-framework sodium cations creates additional preferred adsorption sites in the zeolites at low and intermediate loadings.

In addition, the effect of alkane adsorption on cation distribution was also studied. First, we performed simulations

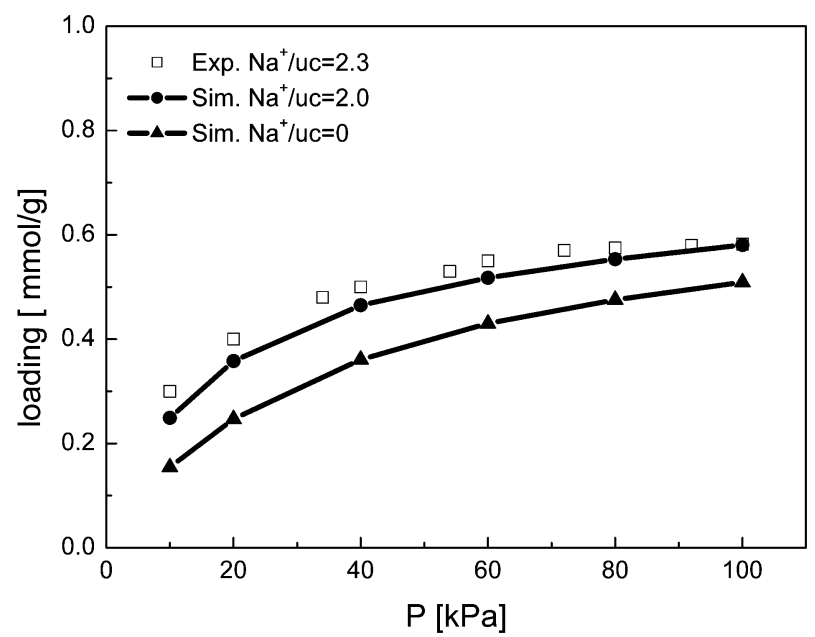

Fig. 5 Comparison of the experimental ${ }^{8}$ and simulated adsorption isotherms of butane in MOR-Na2 zeolite at $438 \mathrm{~K}$.

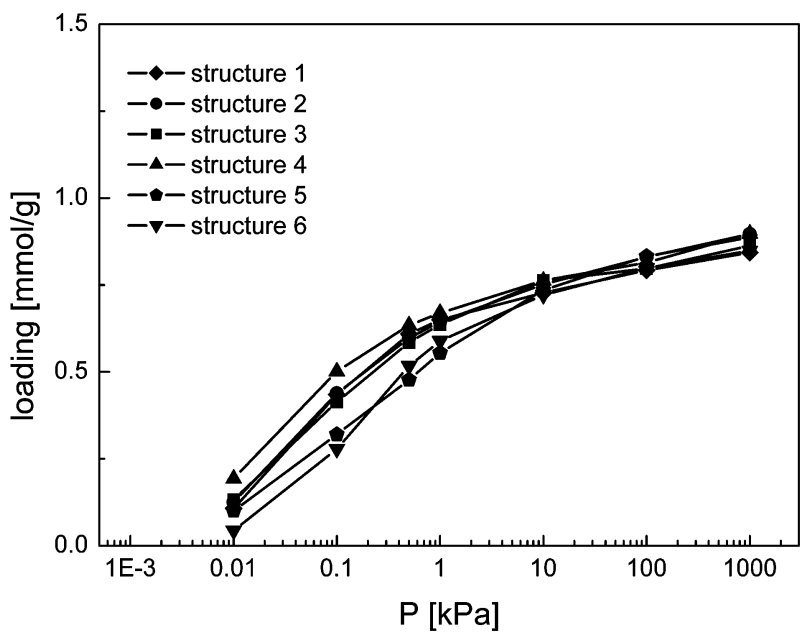

Fig. 6 Simulated adsorption isotherms of $n$-butane in six MOR-Na6 zeolites at $343 \mathrm{~K}$.

on the adsorbate-free MOR with $8 \mathrm{Al}$ atoms per unit cell. Nearly half of the sodium cations were found to reside at site I. These results agree with the available experimental data ${ }^{25,35}$ and further confirm the applicability of the force field. Next, butane adsorption was simulated at $300 \mathrm{~K}$ from 0.01 to 1000 $\mathrm{kPa}$. The results show that the presence of butane in the zeolites does not significantly influence the distribution of cations between site I and the main channel, in spite of the fact that the number of possible $\mathrm{Na}^{+}$cation positions in the main channel is increased by the presence of butane. Site I is located midway between the 12-ring pores in both the [100] and [010] directions; this area of the zeolite is very constrained, i.e. not accessible to butane. This explains the difference in behavior between MOR and FAU, it is found in the latter that the adsorption of butane redistributes the sodium cations. ${ }^{23}$

\subsection{Adsorption isotherms for linear $\mathbf{C}_{5}-\mathbf{C}_{7}$}

From both scientific and practical points of view, larger alkanes are important. We computed the adsorption isotherms

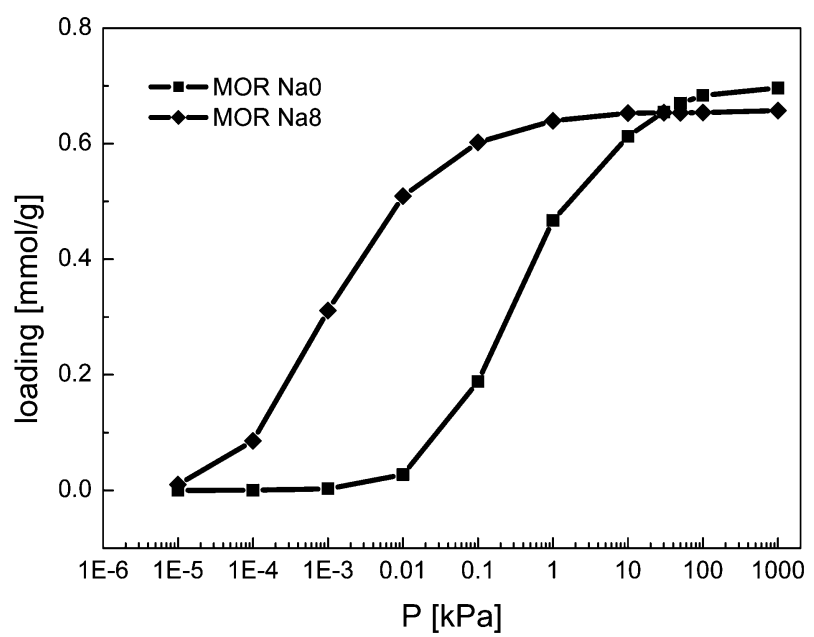

Fig. 7 Simulated adsorption isotherms of $n$-pentane in MOR-type zeolites with 0 and 8 sodium cations per unit cell at $343 \mathrm{~K}$. 


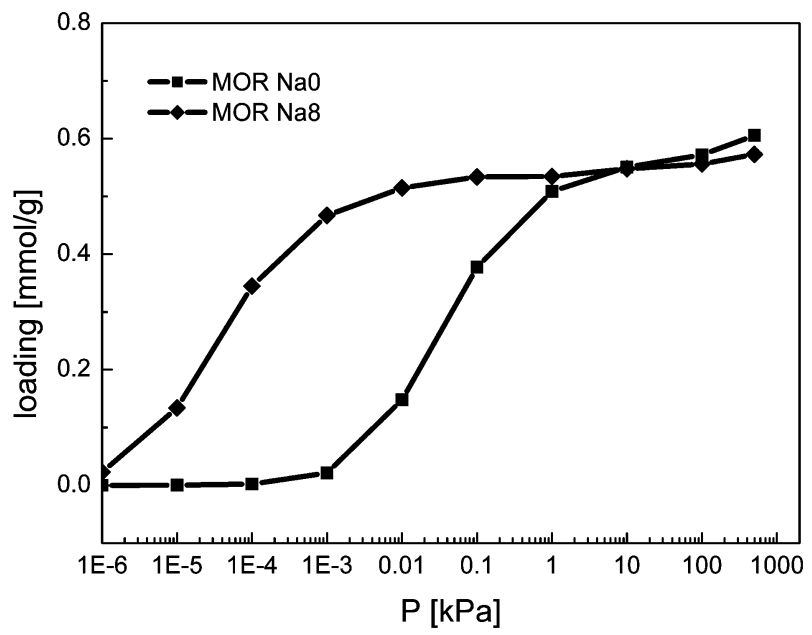

Fig. 8 Simulated adsorption isotherms of $n$-hexane in MOR-type zeolites with 0 and 8 sodium cations per unit cell at $343 \mathrm{~K}$.

of $\mathrm{C}_{5}-\mathrm{C}_{7}$ in $\mathrm{Na}_{8} \mathrm{Al}_{8} \mathrm{Si}_{40} \mathrm{O}_{96}$ and $\mathrm{Na}_{0} \mathrm{Al}_{0} \mathrm{Si}_{48} \mathrm{O}_{96}$, corresponding to the highest and lowest $\mathrm{Al} / \mathrm{Si}$ ratios for $\mathrm{Na}-\mathrm{MOR}$. The simulation results are shown in Fig. 7-9.

Fig. 7 shows that, at low pressures, the pressure needed to reach a given loading in the structure without cations is up to 3 orders of magnitude higher than the pressure required in the cationic structure. At elevated pressures, the amount adsorbed in pure silica is higher than that in the structure with cations. As a consequence, there is a well-defined pressure in which the two structures have identical adsorption capacities. These results are attributed to the fact that there are two effects of cations on the adsorption. Cations create additional preferred adsorption sites, which results in increase of adsorption, while they also take up adsorption volume, which results in decrease of the adsorption volume. Which of the two effects dominates the adsorption depends on the loadings for a given zeolite structure. Generally, at low and intermediate loadings the first effect dominates, while at high loadings the second effect takes over. A similar trend is observed for $\mathrm{C}_{6}$ and $\mathrm{C}_{7}$.

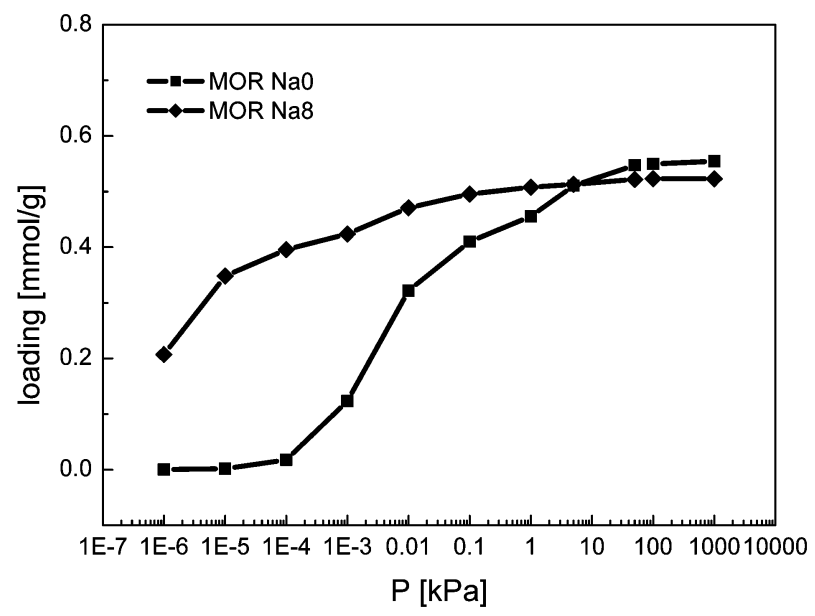

Fig. 9 Simulated adsorption isotherms of $n$-heptane in MOR-type zeolites with 0 and 8 sodium cations per unit cell at $343 \mathrm{~K}$.

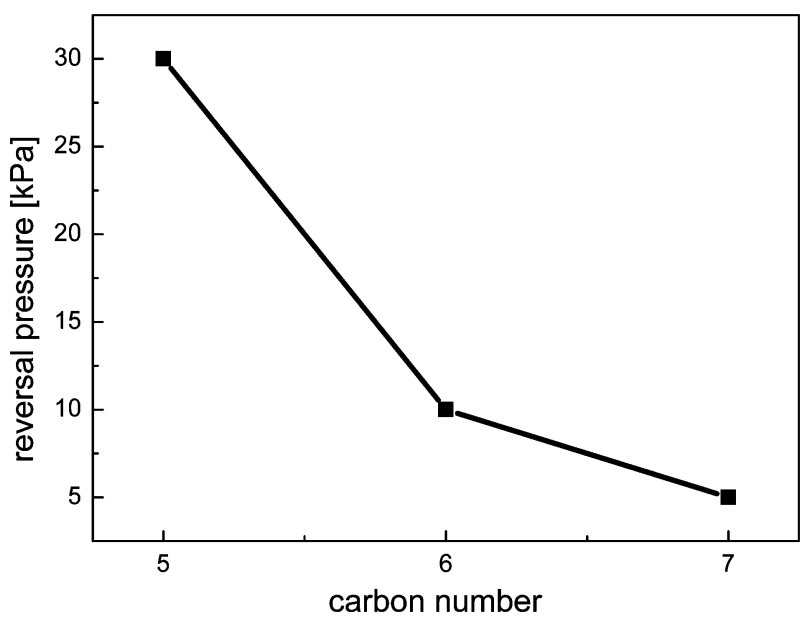

Fig. 10 "Reversal pressure" vs carbon number for $\mathrm{C}_{5}-\mathrm{C}_{7}$ adsorption in MOR at $343 \mathrm{~K}$. The line has been added to guide the eye.

The pressure at which the structures with and without cations show identical adsorption capacities can be called the "reversal pressure", which can be seen as a measure of the effectiveness of the presence of cations (corresponding to the degree of replacement of $\mathrm{Si}$ by $\mathrm{Al}$ in the frameworks), the lower the reversal pressure, the less effective the cations are for augmenting the adsorption. Therefore, the reversal pressure might be a useful quantity that could be considered in designing or selecting zeolites for a particular process.

A comparison of Fig. 7-9 shows that the effect of cations on the adsorption capacity is more pronounced for smaller alkanes, and the "reversal pressure" shifts to lower pressure (lower loadings) for larger alkanes, as shown in Fig. 10. The reason for this is that for a given zeolite structure, the larger the alkane, the larger adsorption volume is required for a certain loading, thus the negative effect of cations on the adsorption (cations take up adsorption volume) occurs at lower loading, compared to smaller alkanes, leading to shifting the "reversal pressure" to lower pressure for larger alkanes. Therefore, it seems that the positive effect of cations on the adsorption capacity of alkanes in zeolites becomes less evident with increasing the carbon number. This should be taken into account when a practical process is to be designed.

\section{Conclusions}

The molecular simulation results presented in this work show that the united-atom force field recently proposed by Calero et al. for $\mathrm{Na}-\mathrm{FAU}$ zeolites is applicable to $\mathrm{Na}-\mathrm{MOR}$ zeolites. Based on this force field, the influence of the location and density of sodium cations on the adsorption behavior of alkanes as well as the adsorption behavior of larger alkanes $\left(\mathrm{C}_{5}-\mathrm{C}_{7}\right)$ in MOR-type zeolites were investigated. In this work the "reversal pressure" was introduced as a measure for the adsorption of alkanes in cation-containing zeolites. For pressures below the reversal pressure, cations enhance the adsorption, while above the reversal pressure the effects of cations decrease the adsorption. In addition, this work shows that the enhancement of adsorption caused by the presence of cations 
becomes weaker with increasing the alkane length. As a result, the present work not only demonstrates that the new force field is suitable for $\mathrm{Na}-\mathrm{MOR}$ zeolites, but also provides some useful molecular-level information of the adsorption behavior of alkanes in $\mathrm{Na}-\mathrm{MOR}$ zeolites, that could contribute to a better understanding of the mechanisms of alkane adsorption in zeolites.

\section{Acknowledgements}

This work is supported by the Dutch STW/CW program Separation Technology (700.56.655-DPC.6243). We thank E. Beerdsen and D. Dubbeldam for useful discussion and $\mathrm{S}$. Calero and $\mathrm{W}$. Zhu for their comments on our manuscript.

\section{References}

1 J. A. van Bokhoven, M. Tromp, D. C. Koningsberger, J. T. Miller, J. A. Z. Pieterse, J. A. Lercher, B. A. Williams and H. H. Kung, J. Catal., 2001, 202, 129.

2 C. N. Satterfield and A. J. Frabetti Jr, AIChE J., 1967, 13, 731.

3 V. R. Choudhary, S. Mayadevi and A. Pai Singh, J. Chem. Soc. Faraday Trans., 1995, 91, 2935.

4 P. E. Eberly Jr, J. Phys. Chem., 1963, 67, 2404.

5 Q. Xu, T. Eguchi, H. Nakayama and N. Nakamura, J. Chem. Soc. Faraday Trans., 1995, 91, 2949.

6 Q. Xu, T. Eguchi, H. Nakayama and N. Nakamura, J. Chem. Soc. Faraday Trans., 1996, 92, 1039.

7 J. F. Denayer, G. V. Baron, J. A. Martens and P. A. Jacobs, J. Phys. Chem. B, 1998, 102, 3077.

8 C. E. Webster, A. Cottone, III and R. S. Drago, J. Am. Chem. Soc., 1999, 121, 12127

9 M. D. Macedonia, D. D. Moore and E. J. Maginn, Langmuir, 2000, 16, 3823.

10 T. Yamazaki, K. Hasegawa, Honma Ken-ichi and S. Ozawa, Phys. Chem. Chem. Phys., 2001, 3, 2686.

11 S. Yuvaraj, T. H. Chang and C. T. Yeh, J. Phys. Chem. B, 2003, 107, 4971.

12 I. Salla, T. Montanari, P. Salagre, Y. Cesteros and G. Busca, $J$. Phys. Chem. B, 2005, 109, 915.

13 B. Smit and C. J. J. den Ouden, J. Phys. Chem., 1988, 92, 7169.
14 E. Beerdsen, B. Smit and S. Calero, J. Phys. Chem. B, 2002, 106, 10659.

15 L.-H. Lu, Q. Wang and Y.-C. Liu, J. Phys. Chem. B, 2005, 109, 8845 .

16 J. M. van Baten and R. Krishna, Microporous Mesoporous Mater., $2005,84,179$.

17 R. L. June, A. T. Bell and D. N. Theodorou, J. Phys. Chem., 1992, 96, 1051.

18 B. Smit, L. D. J. C. Loyens and G. L. M. M. Verbist, Faraday Discuss., 1997, 106, 93

19 T. J. H. Vlugt, R. Krishna and B. Smit, J. Phys. Chem. B, 1999, 103, 1102 .

20 M. D. Macedonia and E. J. Maginn, Mol. Phys., 1999, 96, 1375.

21 P. Pascual, P. Ungerer, B. Tavitian, P. Pernot and A. Boutin, Phys. Chem. Chem. Phys., 2003, 5, 3684.

22 D. Dubbeldam, S. Calero, T. J. H. Vlugt, R. Krishna, T. L. M. Maesen and B. Smit, J. Phys. Chem. B, 2004, 108, 12301.

23 S. Calero, D. Dubbeldam, R. Krishna, B. Smit, T. J. H. Vlugt, J. F. M. Denayer, J. A. Martens and T. L. M. Maesen, J. Am. Chem. Soc., 2004, 126, 11377.

24 E. García-Pérez, I. M. Torréns, S. Lago, D. Dubbeldam, T. J. H. Vlugt, T. L. M. Maesen, B. Smit, R. Krishna and S. Calero, Appl. Surf. Sci., 2005, 252, 716.

25 W. M. Z. Meier, Z. Kristallogr., 1961, 115, 439

26 G. Ricchiardi and J. M. Newsam, J. Phys. Chem. B, 1997, 101, 9943.

27 G. Maurin, P. Senet, S. Devautour, P. Gaveau, F. Henn, V. E. van Doren and J. C. Giuntini, J. Phys. Chem. B, 2001, 105, 9157.

28 T. J. H. Vlugt and M. Schenk, J. Phys. Chem. B, 2002, 106, 12757.

29 J. P. Ryckaert and A. Bellemans, Faraday Discuss. Chem. Soc., 1978, 66, 95.

30 D. Frenkel and B. Smit, Understanding Molecular Simulations: From Algorithms to Applications, Academic Press, San Diego, CA, 2nd edn, 2002.

31 S. Buttefey, A. Boutin, C. Mellot-Draznieks and A. H. Fuchs, $J$ Phys. Chem. B, 2001, 105, 9569.

32 S. P. Bates, W. J. M. van Well, R. A. van Santen and B. Smit, $J$. Am. Chem. Soc., 1996, 118, 6753

33 S. P. Bates, W. J. M. van Well, R. A. van Santen and B. Smit, J. Phys. Chem., 1996, 100, 17573.

34 G. Maurin, R. G. Bell, S. Devautour, F. Henn and J. C. Giuntini, J. Phys. Chem. B, 2004, 108, 3739.

35 International Zeolite Association, Structure Commission, http:// www.iza-structure.org. 